\title{
Too much of a good thing?
}

$\mathrm{O}$ dd though it may sound, experts say Canada may be doing too good a job of handling hazardous medical waste produced in the nation's hospitals.

While the world may be increasingly awash in hazardous medical waste that is not being properly handled and treated, according to a United Nations report (www.cmaj.ca/lookup/doi /10.1503/cmaj.109-4032), Canadian administrators may be overly fastidious in their efforts, driving up costs to the health care system, hospital and wastemanagement administrators claim.

Blurred or poorly-understood definitions of what constitutes hazardous medical waste, improper segregation of hazardous and nonhazardous waste, and inadequate training of staff about the handling and disposal of hazardous materials are all contributing to the waste of resources, they add.

"In any kind of medical waste treatment, proper segregation and sorting is critical and you'd think that was a given but it's not," says Janet Brown, director of sustainable operations for Practice Greenhealth, a nonprofit organization created in 2001 by the American Hospital Association, the United States Environmental Protection Agency and other bodies to help hospitals across North America adopt proper pollution prevention policies in health care facilities.

Mis-sorting is typically the product of a lack of education and training of health care workers about what constitutes hazardous waste, Brown says, adding that many hospital workers simply include materials in the hazardous waste category when they are in doubt.

Regulated medical waste, she says, is anything that's bloody, saturated with body fluid, contains an infectious agent or is an outdated vaccine or drug. Items such as diapers or intravenous bags and tubing do not need to be treated but are often tossed into hazardous waste containers, Brown adds. "The reason it matters is that treating the regulated

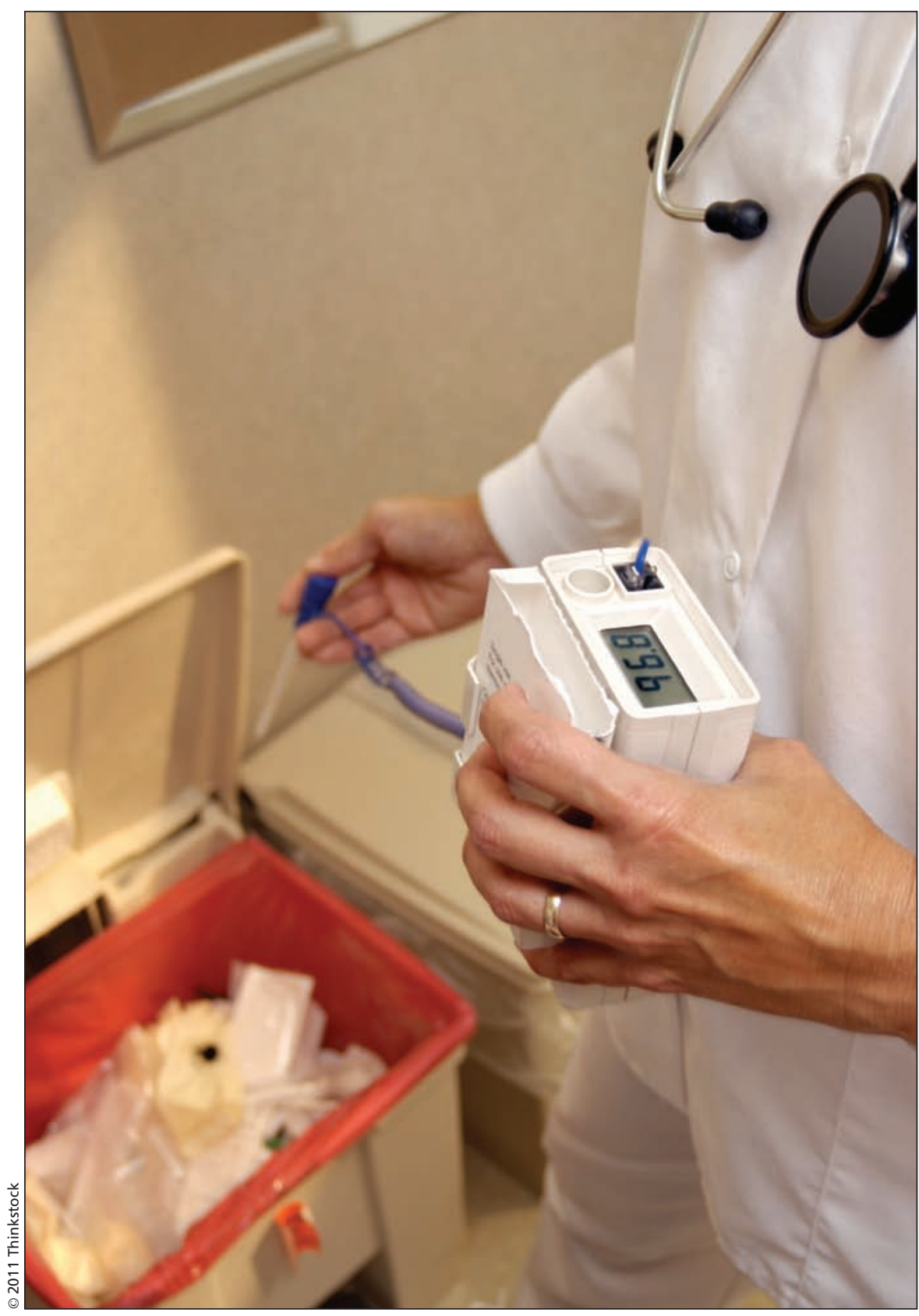

A nurse discards part of an electronic thermometer.

medical waste costs at least five times more than regular waste disposal. So hospitals are just putting dollars into the garbage can. It's just a real waste of resources."

That's likely happening in most hospitals, whether in Canada or abroad, says Edward Rubinstein, manager of energy and environment at the University Health Network in Toronto, Ontario.

The key to keeping disposal methods cost-effective and reducing emissions is accurate sorting of materials to minimize the waste that needs to be either treated or incinerated, as opposed to being shipped to landfills, Rubinstein says. 
Canadian regulations should be modified so that all items saturated with blood aren't automatically considered hazardous waste, Rubinstein adds. "There's very little evidence or no evidence that it's actually an infections hazard. A lot of it is the so called 'ick' factor. It looks gross. No one wants to see these things ending up in the landfill so the legislation is to have it treated."

Rubinstein adds that domestic, residential garbage often contains bloodsoaked materials that don't require special treatment. "Nobody really notices it but when it comes out of the hospital, there's extra attention."

While incineration is required for certain hazardous materials, such as pharmaceutical and pathological waste, the bulk of medical waste can be treated through non-incineration technologies which don't require the addition of chemicals and rely on steam or heat to sterilize the material, such as autoclaving.

Autoclaving "basically just means you're cooking the garbage. It's heated at about 250 degrees Fahrenheit for about 45 minutes just to render the material non-infectious," Brown says.

Practice Greenhealth advocates the use of alternatives such as autoclaving. But Brown warns that "any methodology is only as healthy as what you feed it. So if you put mercury and chemotherapy and all kinds of things into any treatment equipment, it's not healthy."

The handling of mercury is particularly tricky, she adds. Mercury can't be treated in an autoclave and will likely just be aerosolized and health workers would be exposed to the toxic chemical when they open the chamber. As well, mercury can't be incinerated and will simply blow into the atmosphere, which is why hospitals should make themselves mercury free, she adds.

Rubinstein says Canada's health community has made vast strides in medical waste disposal over the past decade. Ten years ago, "even though there were regulations and stuff like that, many people weren't aware of them. And at least in Ontario, they weren't strongly enforced."

Government regulations are much stricter and inspections more frequent, he adds.

But Brown says day-to-day miscues still occur, particularly as a result of the constant transfer of medical equipment and materials. "There are too many cooks in the kitchen," she says, from the person who uses a medical device, to the person who takes it away from the patient, to the person who cleans up a spill. "Even if you have the protocol for safe cleanup of spills or proper segregation for disposal, there are a lot of opportunities for making a mistake."

Educating and training staff must be an ongoing focus of waste management, says Jessica Heiss, sustainability coordinator for the Ottawa Hospital. "We got all the processes set up for getting rid of [biomedical waste] but obviously the important part is making sure the staff that are separating this waste are getting it right." - Erin Walkinshaw, Mississauga, Ont.

CMAJ 2011. DOI:10.1503/cmaj.109-4033

Editor's note: Second of two-part series

Part I: Medical waste management practices vary across Canada (www.cmaj.ca/lookup/doi/10.1503 /cmaj.109-4032) 